Brendan C. O'Kelly', Ph.D. and Patrick J. Naughton ${ }^{2}$, Ph.D.

\title{
Development of a new hollow cylinder apparatus for stress path measurements over a wide strain range
}

\begin{abstract}
The development and operation of a new, automated hollow cylinder apparatus that facilitates accurate stress path measurements from the pseudo elastic domain to failure strain levels are described. Innovative sample loading mechanisms of $19.3 \mathrm{kN}$ axial and 103 N.m torsional capacities facilitate rapid, precise (better than $10^{-5} \%$ strain) displacement and rotation of the sample loading piston, with negligible compliance in the mechanisms on reversing the direction of piston motion. Both internal and external instrumentation are used to record the sample deformational response to better than $10^{-2} \%$ strain. Significant differences were found between the strain values measured using the internal and external instrumentation, with the external instrumentation underestimating the true stiffness of the sample. A series of drained stress-path tests on Leighton Buzzard sand specimens showed that predefined stress paths can be followed to an accuracy of $0.5 \mathrm{kPa}$ using the new apparatus.
\end{abstract}

KEYWORDS: hollow cylinder apparatus, generalized stress path, small strain, automation

\begin{tabular}{ll} 
Symbols & \\
$\mathrm{b}$ & Intermediate principal stress parameter \\
$\mathrm{H}$ & Sample height \\
$\mathrm{H}_{\mathrm{i}}$ & Initial sample height \\
$\mathrm{p}_{\mathrm{i}}$ & Inner bore pressure \\
$\mathrm{p}_{\mathrm{o}}$ & Outer cell pressure \\
$\mathrm{r}_{\mathrm{i}}$ & Inner sample radius \\
$\mathrm{r}_{\mathrm{o}}$ & Outer sample radius \\
$\mathrm{R}, \mathrm{R}$ & Total and effective major-minor principal stress ratios \\
$\mathrm{T}$ & Torque \\
$\mathrm{u}$ & Pore water pressure \\
$\mathrm{v}$ & Axial deformation \\
$\mathrm{W}_{\mathrm{i}}$ & Displacement of inner sample wall \\
$\mathrm{W}_{\mathrm{o}}$ & Displacement of outer sample wall \\
$\mathrm{W}$ & Axial load \\
$\alpha_{\sigma}$ & Rotation of major principal stress relative to the vertical direction \\
$\gamma_{z \theta}$ & Circumferential shear strain \\
$\varepsilon_{z}, \varepsilon_{r}, \varepsilon_{\theta}$ & Axial, radial and circumferential normal strains \\
$\varepsilon_{v o l}$ & Volumetric strain \\
$\varepsilon_{1}, \varepsilon_{2}, \varepsilon_{3}$ & Major, intermediate and minor principal strains \\
$\sigma_{\mathrm{m}}, \sigma_{\mathrm{m}}$ & Mean total and effective confining stresses \\
& \\
\hline
\end{tabular}

\footnotetext{
${ }^{1}$ Lecturer, Department of Civil, Structural and Environmental Engineering, University of Dublin, Trinity College, Dublin 2, IRELAND, and formerly Scott Wilson Consulting Engineers, UK.

${ }^{2}$ Lecturer, School of Engineering, Institute of Technology, Sligo, IRELAND.
} 


$\begin{array}{ll}\sigma_{z}, \sigma_{r}, \sigma_{\theta} & \text { Mean axial, radial and circumferential total normal stresses } \\ \sigma_{z}{ }^{\prime}, \sigma_{r}{ }^{\prime}, \sigma_{\theta}{ }^{\prime} & \text { Mean axial, radial and circumferential effective normal stresses } \\ \sigma_{1}, \sigma_{2}, \sigma_{3} & \text { Major, intermediate and minor total principal stresses } \\ \sigma_{1}{ }^{\prime}, \sigma_{2}{ }^{\prime}, \sigma_{3}{ }^{\prime} & \text { Major, intermediate and minor effective principal stresses } \\ \theta & \text { Circumferential shear deformation } \\ \tau_{z \theta} & \text { Mean circumferential shear stress }\end{array}$

\section{Introduction}

The hollow cylinder apparatus is an extremely valuable tool for studying soil constitutive behavior under generalized stress conditions. Most sedimentary soils are inherently anisotropic. Consequently, ground deformations can occur due to changes in both the magnitudes and the directions of the principal stresses. The hollow cylinder apparatus allows independent control of the magnitude of the principal stresses and rotation, $\alpha_{\sigma}$, of the major-minor principal stress axes while recording the sample deformational and pore pressure responses, thus facilitating more generalized stress path testing than conventional test apparatus.

Stress path testing necessitates precise closed-loop control of the applied sample loads and confining pressures and accurate measurement of the sample deformational and pore pressure responses. Compliance in the sample loading mechanisms impacts on the control efficiency and may arise, for example, in the mechanism that torques the sample loading piston whenever the load direction is reversed (Saada and Puccini, 1986).

Lo Presti et al. (1993) reported that reliance on external measurement of the sample deformations can cause significant errors and they suggested that, where possible, internal instrumentation should be used. A further consideration for hollow cylinder testing is the selection of suitable test specimen dimensions. A non-uniform stress distribution develops across the sample wall thickness whenever a torque or unequal confining pressures are applied due to the curvature of the sample walls (Wijewickreme and Vaid, 1991).

A new hollow cylinder apparatus was recently developed at the Department of Civil Engineering, University College Dublin, Ireland. The apparatus facilitates accurate measurements of the constitutive and pore pressure responses of soil over a wide strain range under generalized stress conditions. The innovative features of the apparatus, in particular those that achieve the necessary control for accurate stress path testing over the small-strain domain, are described. The efficiency of the new apparatus is demonstrated using stress path test data for sand.

\section{Principle of hollow cylinder testing}

The apparatus tests a thick-walled hollow cylindrical sample, $100 \mathrm{~mm}$ outer diameter, $71 \mathrm{~mm}$ inner diameter and $200 \mathrm{~mm}$ long. Hydrostatic confining pressures, $\mathrm{p}_{\mathrm{o}}$ and $\mathrm{p}_{\mathrm{i}}$, are applied to the outer and inner sample walls, respectively, Fig. 1(a). Axial (W) and torsional (T) loads are applied to the sample ends via annular loading platens. Fig. 1 (b) shows the resulting axial (v), radial $\left(\mathrm{w}_{\mathrm{o}}, \mathrm{w}_{\mathrm{i}}\right)$ and circumferential shear $(\theta)$ sample deformations.

Four non-zero stresses $\left(\sigma_{\mathrm{z}}, \sigma_{\mathrm{r}}, \sigma_{\theta}, \tau_{\mathrm{z} \theta}\right)$ are induced in an element of the sample wall (Fig. 1(c)). The magnitudes of these stresses are calculated from the applied loads, confining pressures and the sample deformational response. The radial confining stress $\left(\sigma_{\mathrm{r}}\right)$ is the intermediate principal stress. Hence, torque application 
causes rotation $\left(\alpha_{\sigma}\right)$ of the major-minor principal stress axes in the vertical plane (Fig. 1(d)). The direction of the major-minor principal stress axes is resolved from the four induced sample stresses using the Mohr-Circle of Stress analysis. The relative value of the intermediate principal stress is quantified in terms of the intermediate principal stress parameter, $b$. The $b$ parameter has a range of 0 to 1 . With $b=0$, the intermediate and minor principal stresses are equal, while with $b=1$ the intermediate and major principal stresses are equal.

\section{Sample dimensions and stress non-uniformity}

The sample dimensions selected limit the development of stress non-uniformity in the test specimen to an acceptable level under generalized stress conditions. The outer diameter was chosen to facilitate tests on undisturbed samples of $100 \mathrm{~mm}$ diameter, with the minimum of additional disturbance caused during sample preparation.

(a)

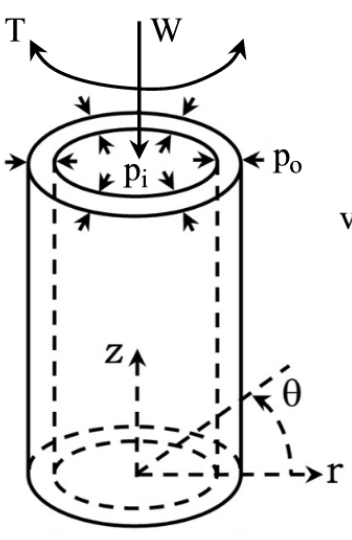

(b)

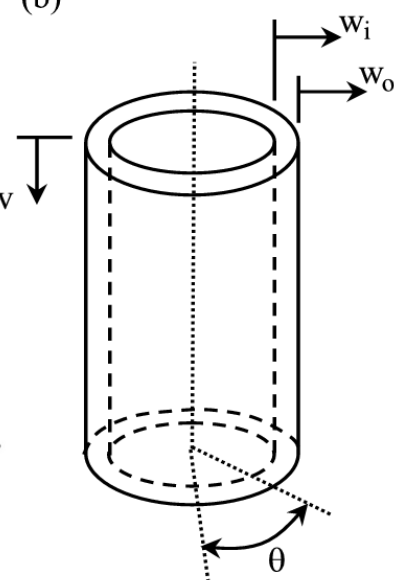

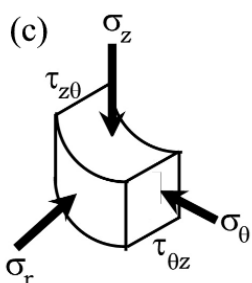

(d)

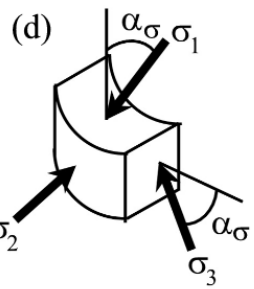

(a) Applied loads and pressures; (b) Deformations; (c) Induced stresses; (d) Principal stresses.

FIG. 1-Stress and deformation states for the hollow cylindrical sample.

A numerical analysis indicated that these diametrical dimensions resulted in a reasonably homogeneous stress distribution (according to the criteria set out by Vaid et al. (1990)) acting across the sample wall thickness under generalized stress conditions. The analysis employed a linear-elastic constitutive model and the results, therefore, most realistically indicate potential levels of stress non-uniformity that may arise during tests over the pseudo elastic domain. The analysis indicated that the largest stress non-uniformity may arise in the region of $\alpha_{\sigma}=45^{\circ}$ for all values of the $b$ parameter, and also at $\alpha_{\sigma}=0^{\circ}$ with $b=1.0$, and $\alpha_{\sigma}=90^{\circ}$ with $b=0$. Stress nonuniformity also arises due to the effects of sample end restraint (Tatsuoka et al., 1986). The standard sample aspect ratio for laboratory compression testing of 2:1 was adopted with the use of internal instrumentation deployed over the mid-third of the sample length.

\section{Overview of the new apparatus}

The apparatus consists of the test specimen contained within a pressure cell that is mounted on a table, Fig. 2. The axial and torsional loading mechanics are secured to the reaction frame located beneath the pressure cell. Sample load, torque, pressure and deformation instruments are located both inside and outside the pressure cell. The 
traditional apparatus layout was rearranged so that the new apparatus is more compact (approximately $1.0 \mathrm{~m}$ square by $1.5 \mathrm{~m}$ high) and it is easier to set up a test specimen and assemble the pressure cell.

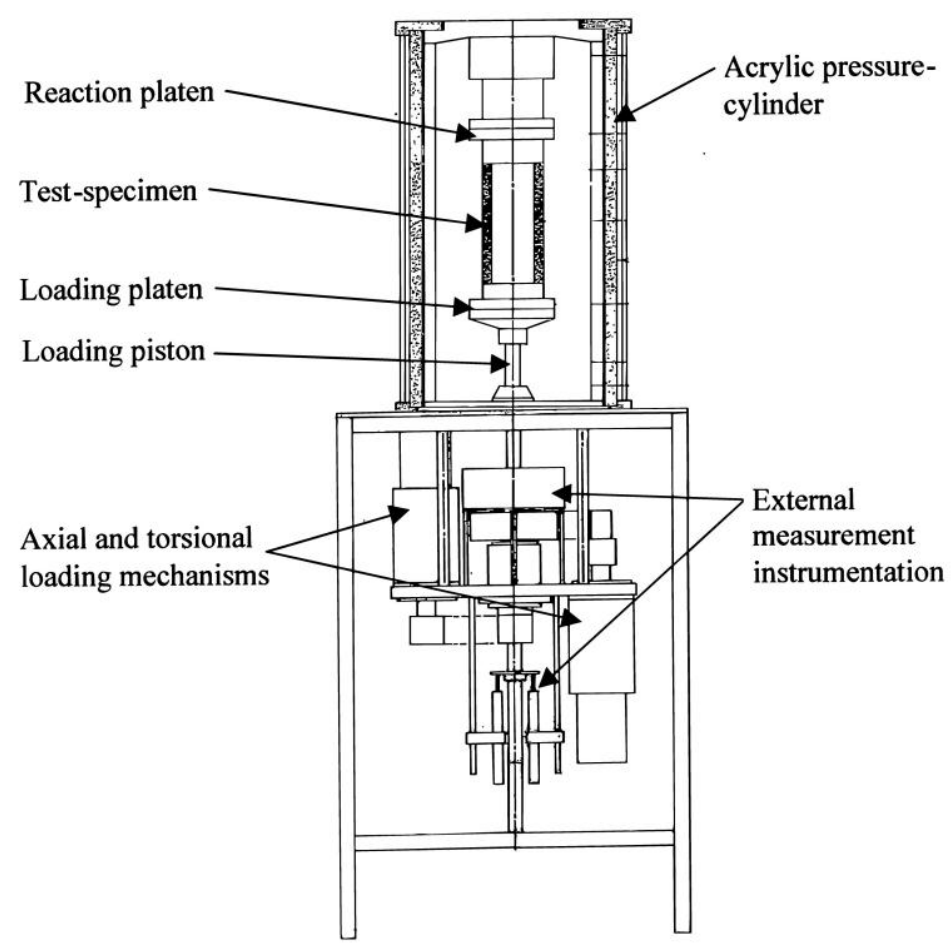

Fig. 2. Schematic of new apparatus.

The ends of the hollow cylindrical sample are in contact with annular loading platens inside an acrylic cylinder which is $340 \mathrm{~mm}$ diameter by $600 \mathrm{~mm}$ high. The outer cell chamber, the test specimen and its inner bore cavity are independently sealed. Hydrostatic confining pressures are applied via rubber membranes to the inner and outer walls of the specimen. Axial and torsional loads are applied to the base of the specimen via a loading piston while the top end of the specimen is restrained. Rough, annular sintered bronze discs that are fastened to the loading platens facilitate sample drainage. Eight thin radial blades that protrude $1.5 \mathrm{~mm}$ above the annular discs prevent slippage at the specimen ends when a torsional load is applied. The load reaction cage, located inside the acrylic cylinder, is bolted to the reaction frame, positioned beneath the cell base. One of the innovative features of the new apparatus is the zero-backlash mechanisms that displace and rotate the sample loading piston.

\section{Loading mechanisms and reaction frame}

Screw and spline ball bearings (manufactured by THK Co. Ltd., Japan) which are secured to the reaction frame, actuate and support the sample loading piston (Fig. 3). Precision screw and spline grooves were machined along the lower section of the 25.0 $\mathrm{mm}$ diameter piston, which was case hardened. The upper section of the piston, which passes thought the cell base, was chrome plated, ground and polished. The rubber ring sealing the cell entry point was coated with polytetrafluoroethylene to facilitate smooth piston motion. Rotation of the screw and spline bearings in different sequences produces smooth vertical, rotary or spiral piston motion. 
Two drive units, comprising 1.8 degree stepping motors fitted with precision 1:100 gearboxes, actuate the bearings. Tensioned steel cables link the bearings around the piston, and the pulleys fitted to the drive units. The $5 \mathrm{~mm}$ diameter, braided steel cables are wrapped around the pulley pairs, coiled left-handed on one pulley and right-handed on the other (Fig. 3). The loading piston can be displaced and rotated in 0.1 micron and 0.8 arc-second steps, respectively, which is equivalent to a strain control resolution of better than $7 \times 10^{-5} \%$ strain. Compliance in the loading mechanism was controlled by tensioning the steel cables to $1.4 \mathrm{kN}$ during fabrication of the apparatus.

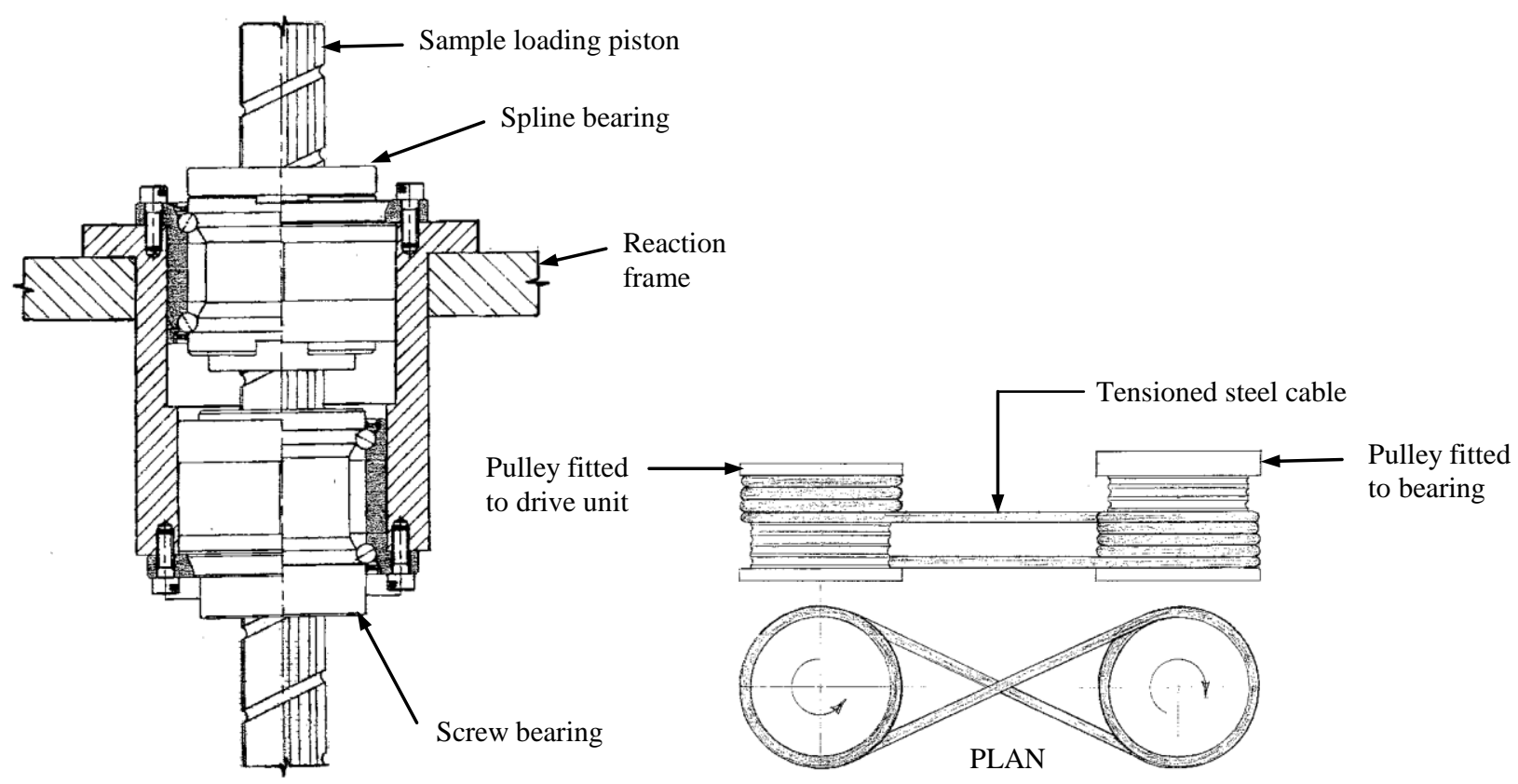

FIG. 3-(a) Screw and spline bearings that actuate the loading piston. (b) Configuration of steel cables linking pulley pairs.

The steel balls in the bearings were also replaced with balls of slightly larger diameter to lightly preload the bearings. The operating working loads of the mechanisms are $19.3 \mathrm{kN}$ axial and \pm 103 N.m torsional, and correspond to unconfined compressive and circumferential shear stresses of 5.0 MPa and 0.6 MPa, respectively, over the sample cross-section. The compliance in the loading mechanisms displayed no lag during stress path reversals, Fig. 4. The radial normal strain and circumferential shear strain display similar patterns to their respective stress components. The sample stress and strain components are resolved to $0.25 \mathrm{kPa}$ and $0.5 \times 10^{-3} \%$ strain.

The stainless steel reaction cage, positioned inside the acrylic cylinder, resists the axial and torsional loads applied across the sample length. The top and base plates of the pressure cell are linked by six $20 \mathrm{~mm}$ diameter stainless steel bars, two of which are adjustable in length so that they can be removed prior to setting up a test specimen to facilitate easy access inside the cell chamber. When in place, the length of these bars is set to the correct length using a screw adjustment before the connection is made with the cell top plate. The internal reaction cage facilitates measurement and control of the stresses induced in the test specimen from the moment that the top loading platen and the sample top cap are connected together. Disturbance of the specimen is avoided using this set up. All load-bearing components inside the acrylic 
cylinder are stainless steel. The exception is the aluminum top loading platen which was necessary to keep the axial normal stress that is applied to the unconfined test specimen acceptably low during cell assembly.
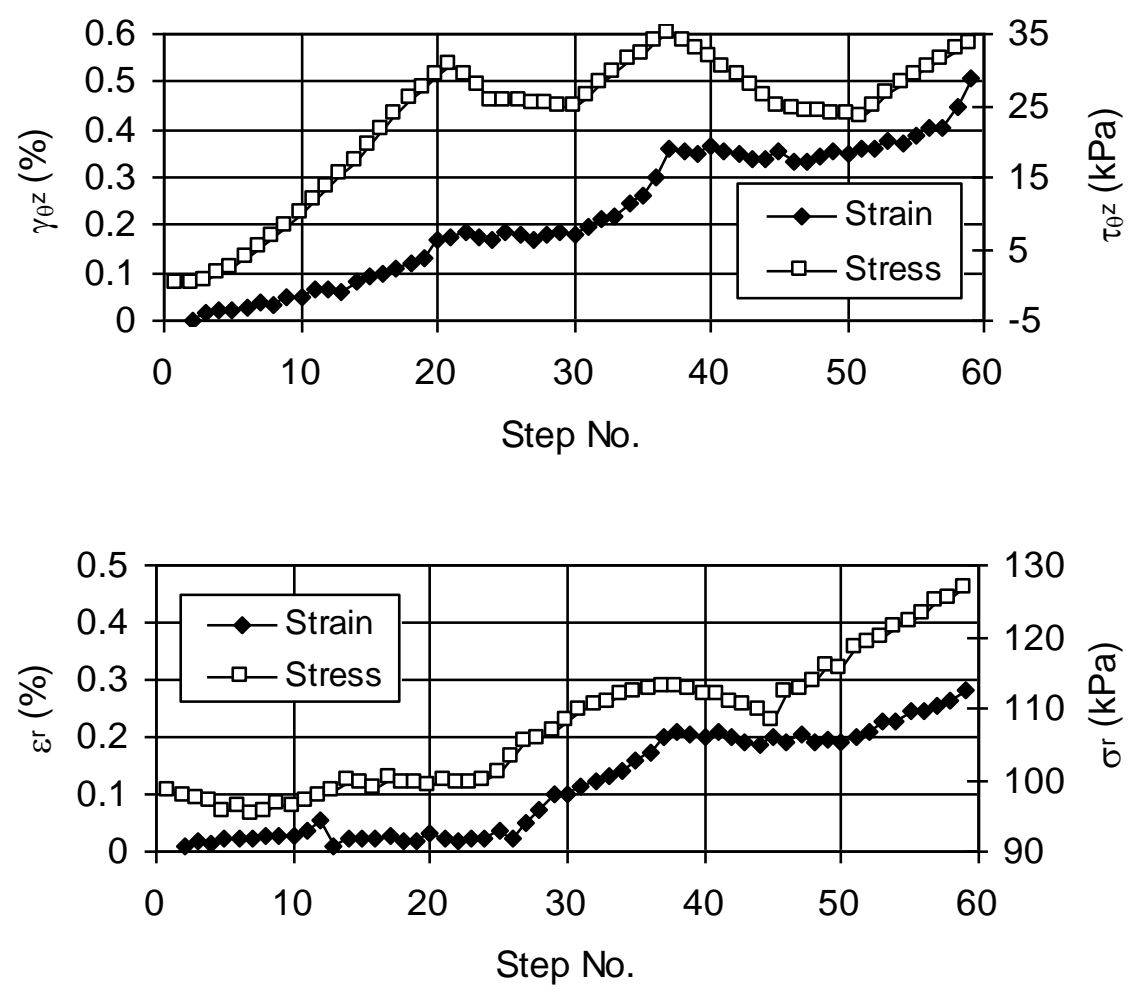

FIG. 4- Sample deformational responses for changes in direction of stress path.

\section{Pressure systems and seals}

Three screw-driven actuators from GDS Instruments Ltd. (1998) pressurize the outer cell chamber, the inner bore cavity, and apply a back pressure to the sample. The actuators have a $2.0 \mathrm{MPa}$ and $200 \mathrm{ml}$ operating range, with automatic adjustment of the applied pressures at a rate of $15 \mathrm{kPa} / \mathrm{s}$. Stainless steel tubing was used for all pressurized lines with the exception of the thick-walled plastic tubing that linked the ports on the sample base pedestal and the cell base plate, due to their relative movement during a test.

\section{Sample preparation and repeatability of specimen properties}

Hollow cylindrical test specimens of well graded, white Leighton Buzzard sand (Table 1) were formed using a wet-pluviation technique (O'Kelly and Naughton, 2004). The specimens of very loose to loose relative density were formed by depositing saturated sand through water, into the annular void formed between inner and outer split moulds. Tapping the side of the outer mould caused the specimen to compact to a target, higher relative density. O'Kelly and Naughton (2004) reported that the specimens can be reproduced to within $2 \%$ of the target void ratio for the test sand. 
TABLE 1—Physical properties of Leighton Buzzard sand.

\begin{tabular}{ccccccc}
\hline Property & $\begin{array}{c}\text { Coefficient } \\
\text { of } \\
\text { uniformity }\end{array}$ & $\begin{array}{c}\text { Coefficient } \\
\text { of } \\
\text { curvature }\end{array}$ & $\begin{array}{c}\mathrm{d}_{50} \\
(\mathrm{~mm})\end{array}$ & $\begin{array}{c}\text { Specific } \\
\text { gravity }\end{array}$ & $\begin{array}{c}\text { Maximum } \\
\text { void ratio }\end{array}$ & $\begin{array}{c}\text { Minimum } \\
\text { void ratio }\end{array}$ \\
\hline Value & 1.32 & 0.96 & 0.52 & 2.64 & 0.80 & 0.53 \\
\hline
\end{tabular}

\section{Instrumentation}

Internal instrumentation comprising inclinometer gauges and proximity transducers facilitate accurate measurement of the sample deformational response over the mid-third of the specimen length. External instrumentation comprising two displacement transducers and a rotary encoder record the global axial and twist deformations of the specimen. The radial displacements of the sample walls were estimated from measured volume changes of the specimen and its inner bore cavity, assuming that the specimen deforms as a right-cylinder. A torque-thrust transducer records the axial load and torque applied over the specimen length.

\section{Measurement of sample deformations}

Inclinometer gauges of the type developed at Imperial College (Burland and Symes, 1982; Symes and Burland, 1984) were reconfigured to produce an instrument with a shorter gauge length (Fig. 5) thus reducing possible errors due to the attachment of the instruments too close to the sample ends. The inclinometers consist of electrolevel capsules sealed inside stainless steel containers. For the single-axis inclinometer, a single electrolevel capsule is used to measure circumferential shear deformations, for the double-axis inclinometer two electrolevel capsules positioned on a mechanism measure the axial and circumferential shear deformations. The inclinometers were powered at $5 \mathrm{~V}$ and give a $50 \mathrm{mV} / 3$ degree sample twist and 50 $\mathrm{mV} / \mathrm{mm}$ axial deformation. The gauges were glued to the outer sample membrane during a test, with the change in inclination of the electrolevel capsules directly related to the axial and circumferential shear deformations of the specimen. Two double-axis inclinometer gauges were located diametrically apart, and a single axis inclinometer gauge was located midway between the double-axis gauges during a test.

The inclinometer gauges were calibrated using an optical table which allowed simultaneous recording of the axial and twist gauge movements to a displacement resolution of $2.5 \mu \mathrm{m}$, which corresponds to a resolution of axial and circumferential shear strains of $1.3 \times 10^{-3} \%$ strain and $4.5 \times 10^{-3} \%$ strain, respectively.

Two proximity transducers, one located in the inner bore cavity, the second located opposite in the outer cell chamber, measured the radial displacements of the inner and outer sample walls. The transducers were positioned next to, and near the mid height of the specimen. These non-contact transducers use the principal of impedance variation to measure the gap between the transducer face and an aluminum foil target attached to the sample membranes using silicone grease (Brown et al. 1980). The attachment of the aluminum foil to the rubber membranes does not affect the deformational response of the specimen (Tatsuoka et al. 1983). 


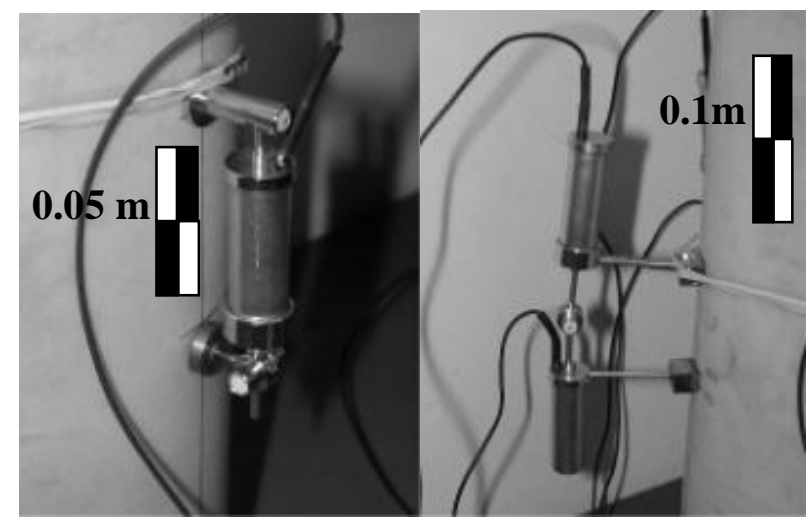

FIG. 5-(a) Single-axis and (b) double-axis inclinometer gauges.

The locations of the proximity transducers was adjusted remotely from outside the pressure cell using precision gearing, which allowed the transducers to be relocated during a test in order to suit the radial displacement response of the specimen. The system design allowed the proximity transducer to be relocated in the inner bore cavity without causing a volume change of the fluid contained in that cavity. The housings that waterproofed the transducers were made of plastic to avoid interference with the electromagnetic fields emanating from the active transducers. Hand-tightened nylon ferrules and rubber rings sealed the transducer housings. The screened cables from the proximity transducers, which form an integral part of the impedance bridge circuit, were isolated from the cell and bore chamber pressures by enclosing them in thick-walled plastic tubing.

The proximity transducers were calibrated to a displacement resolution of $10^{-5}$ $\mathrm{mm}$, corresponding to radial and circumferential shear strains of $7 \times 10^{-5} \%$ strain, using an optical table and laser distance measurement system, with a linear measurement resolution of $10^{-9} \mathrm{~mm}$. Care was taken during calibration and assembly of the apparatus so as not to interfere with the instrument cables. The proximity transducers were calibrated in their housings, which includes the cable ducting. The transducers were calibrated while submerged in water since their responses were found to depend on the medium in which they were operated. The effect of hydraulic pressure on the calibration was not assessed as Menkiti (1995) demonstrated that such pressures did not affect the calibration for this type of instrument.

Sample loads and confining pressures

The thrust-torque transducer (manufactured by Maywood Instruments Ltd., UK) located inside the pressure cell next to the top of the specimen, recorded the applied axial and torsional loads. The transducer was electrically insulated inside an oil-filled housing for which a pressure compensation system was devised so that the transducer measures the actual loads applied. The inside of the housing was saturated with oil and pressurized equal to that of the outer cell pressure, thereby making the transducer readings independent of changes to the cell and bore confining pressures, Fig. 6. The thrust-torque transducer records the axial load to within $1 \mathrm{~N}$ which corresponds to an axial normal stress of approximately $0.25 \mathrm{kPa}$. 


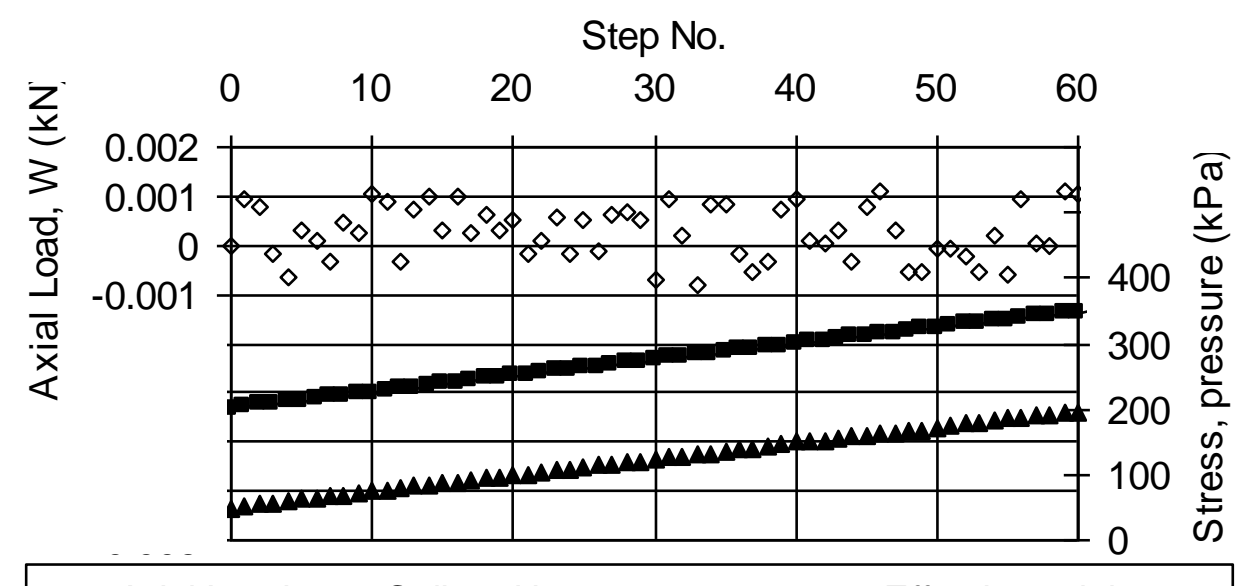

$\diamond \quad$ Axial Load $\rightarrow-$ Cell and bore pressures $\Delta$ Effective axial stress

FIG. 6-Variation of axial load during isotropic load test.

A load frame, which facilitated simultaneous application of the axial and torsional loads, facilitated calibration of the transducer to a resolution of $0.5 \mathrm{~N}$ and $2 \mathrm{~N} . \mathrm{m}$, respectively. The calibration was preformed in air and without oil in the transducer housing.

\section{Stress path control}

A prescribed stress path was followed by sequentially moving between transitional target stress points located along the stress path. The specimen deformations and pore pressure response, were applicable, were brought to equilibrium at each transitional stress point before proceeding to the next point on the stress path. A suite of $\mathrm{LabVIEW}{ }^{\circledR}$ programs that monitored the stress state and deformational response of the specimen facilitated accurate stress path testing.

The instrumentation was connected to a computer for closed-loop control. The pressure actuators were connected via a general purpose interface bus (GPIB) and the drive units for the sample loading piston via a Compumotor ${ }^{\circledR}$ peripheral component interconnect (PCI) card. Two data acquisition (DAQ) systems recorded the deformational response of the specimen. A 24-bit DAQ system was dedicated to the internal instrumentation while a 16-bit DAQ system interfaced with the external instrumentation. Noise reduction was achieved by utilizing the built in noise filters on the DAQ boards and by careful screening of the signal cables. The control program automatically corrected for membrane restraint effects using the corrections developed by Tatsuoka et al. (1986), and for membrane penetration effects using the technique developed by Sivathayalan and Vaid (1998).

Algorithms were incorporated in the control program that enabled the pressure actuators to target a pressure within $0.25 \mathrm{kPa}$, a four fold improvement on that achieved by the standard instrument, and record volume changes to $0.001 \mathrm{ml}$.

\section{Resolution and accuracy of stress-strain measurement}

The range, resolution and accuracy of the load, pressure and deformation instruments, expressed in terms of stress and strain measurement in the test specimen, are listed in Table 2. The strain measurement capability encompasses the full range of soil behavior of engineering interest, from the pseudo-elastic domain of the order of $10^{-3} \%$ strain, to sample failure. 
TABLE 2-Range, resolution and accuracy of stress-strain measurement.

\begin{tabular}{|c|c|c|c|}
\hline Stress component & Range (kPa) & Resolution (kPa) & Accuracy $(\mathrm{kPa})$ \\
\hline$\sigma_{\mathrm{z}}$ & 0 to 700 & 0.015 & 2 \\
\hline$\sigma_{\mathrm{r}}$ & 0 to 700 & 0.2 & 2 \\
\hline$\sigma_{\theta}$ & 0 to 700 & 0.2 & 2 \\
\hline$\tau_{\mathrm{z} \theta}$ & 0 to 295 & 0.004 & 2 \\
\hline Back pressure & 0 to 2000 & 0.2 & 2 \\
\hline Strain component & $\begin{array}{l}\text { Range } \\
\text { (\% strain) }\end{array}$ & $\begin{array}{l}\text { Resolution } \\
\text { (\% strain) }\end{array}$ & $\begin{array}{l}\text { Accuracy } \\
\text { (\% strain) }\end{array}$ \\
\hline \multicolumn{4}{|l|}{ Internal instrumentation } \\
\hline$\varepsilon_{\mathrm{z}}$ & -21 to 21 & $1.3 \times 10^{-3}$ & $7.4 \times 10^{-3}$ \\
\hline$\varepsilon_{\mathrm{r}}$ & -41 to 41 & $6.9 \times 10^{-5}$ & $2.9 \times 10^{-1}$ \\
\hline$\varepsilon_{\theta}$ & -7 to 7 & $1.2 \times 10^{-5}$ & $5.0 \times 10^{-2}$ \\
\hline$\gamma_{\theta z}$ & -24 to 24 & $5.2 \times 10^{-3}$ & $5.7 \times 10^{-3}$ \\
\hline \multicolumn{4}{|l|}{ External instrumentation } \\
\hline$\varepsilon_{\mathrm{z}}$ & -25 to 25 & $5.0 \times 10^{-3}$ & $1.8 \times 10^{-2}$ \\
\hline$\gamma_{\theta z}$ & $\infty$ & $6.8 \times 10^{-3}$ & $6.7 \times 10^{-4}$ \\
\hline
\end{tabular}

\section{Governing equations and relationships}

The mean sample stresses were related to the applied axial load, torque and confining pressures by considering the sample as a thick-walled hollow cylinder with an isotropic linear-elastic constitutive response. The axial, radial and circumferential normal stresses were derived from equilibrium considerations, with the circumferential shear stress derived assuming a linear distribution of shear stress across the sample wall thickness. In all cases, the sample stresses were averaged over the sample volume.

The radial and circumferential normal strains were written in terms of the inner and outer sample wall displacements by assuming a linear variation of radial displacement across the sample wall thickness. The axial displacement was assumed positive downwards and to be uniformly distributed over the horizontal crosssectional area of the sample. The circumferential shear strain was written in terms of the sample twist assuming that no tangential displacement occurred in symmetric fields. The equations for the mean values of the stress and strain components are presented in Table 3.

TABLE 3 - Sample stress and strain equations.

\begin{tabular}{lcc}
\hline Axis direction & Mean stress & Mean strain \\
\hline Axial normal & $\sigma_{z}=\frac{W}{\pi\left(r_{o}{ }^{2}-r_{i}^{2}\right)}+\frac{p_{o} r_{o}{ }^{2}-p_{i} r_{i}^{2}}{r_{o}{ }^{2}-r_{i}^{2}}$ & $\varepsilon_{z}=\frac{v}{H_{i}}$ \\
Radial normal & $\sigma_{r}=\frac{p_{o} r_{o}{ }^{2}-p_{i} r_{i}{ }^{2}}{r_{o}{ }^{2}-r_{i}{ }^{2}}-\frac{2 r_{i}{ }^{2} r_{o}{ }^{2}\left(p_{o}-p_{i}\right) \ln \left(r_{o} / r_{i}\right)}{\left(r_{o}{ }^{2}-r_{i}{ }^{2}\right)^{2}}$ & $\varepsilon_{r}=-\left(\frac{w_{o}-w_{i}}{r_{o}-r_{i}}\right)$ \\
& & \\
\hline
\end{tabular}




\begin{tabular}{|c|c|c|}
\hline $\begin{array}{l}\text { Circumferential } \\
\text { normal }\end{array}$ & $\sigma_{\theta}=\frac{p_{o} r_{o}^{2}-p_{i} r_{i}^{2}}{r_{o}^{2}-r_{i}^{2}}+\frac{2 r_{i}^{2} r_{o}^{2}\left(p_{o}-p_{i}\right) \ln \left(r_{o} / r_{i}\right)}{\left(r_{o}^{2}-r_{i}^{2}\right)^{2}}$ & $\varepsilon_{\theta}=-\left(\frac{w_{o}+w_{i}}{r_{o}+r_{i}}\right)$ \\
\hline $\begin{array}{l}\text { Circumferential } \\
\text { shear }\end{array}$ & $\tau_{z \theta}=\frac{4 T\left(r_{o}^{3}-r_{i}^{3}\right)}{3 \pi\left(r_{o}^{4}-r_{i}^{4}\right)\left(r_{o}^{2}-r_{i}^{2}\right)}$ & $\gamma_{z \theta}=\frac{2 \theta\left(r_{o}^{3}-r_{i}^{3}\right)}{3 H\left(r_{o}^{2}-r_{i}^{2}\right)}$ \\
\hline
\end{tabular}

The equations used to define the mean sample stresses are similar to those used by Vaid et al. (1990). The equations for calculating the mean sample strains are similar to those used by Vaid et al. (1990), Ampadu et al. (1993), Hight et al. (1983) and Miura et al. (1986).

\section{Assessment of apparatus capabilities}

The ability of the new apparatus to follow prescribed stress paths was assessed for both isotropic and anisotropic sample loading conditions. Test data presented for anisotropic stress path reversals and undrained sample loading to failure demonstrated the apparatus capability to accurately target a stress path and record the sample deformational response.

\section{Isotropic load test}

The isotropic load test involved increasing the mean effective stress, $\sigma_{\mathrm{m}}$ ', in three identical test specimens from 50 to $200 \mathrm{kPa}$ against an applied back pressure of 150 $\mathrm{kPa}$. The test specimens, designated I, II and III, had initial voids ratio of $0.60,0.58$ and 0.61 respectively, and were saturated using an elevated back-pressure technique, similar to that employed by Porovic (1993). The principal strains recorded using the internal instrumentation displayed good agreement, given the slight variability of the initial void ratios, indicating the efficiency of stress path control achievable, Fig. 7. Good agreement was observed between the internal and external measurements of the major principal strain indicating good compliance of the axial loading mechanism. Significant variations in the intermediate and minor principal strains calculated using the external measurements are evident. These variations were attributed to inaccuracies in measuring the volume changes of the inner bore cavity and the specimen itself. The volumetric strain, calculated from the sample volume changes are lower, but generally agreed with the summation of the three principal strains determined using the internal instrumentation, Fig. 7. Overall, the variation in the magnitudes of the external and internal strain values are consistent with other studies (Lo Presti et al. 1993). The deformational response of the specimen recorded by the internal instruments was used for all stress and strain calculations in the control program.

\section{Anisotropic loading}

Anisotropic stress paths between two stress states were used to demonstrate the apparatus capability to smoothly rotate the major principal stress while also accurately changing the magnitude of the individual principal stresses. The same stress state of $\sigma_{\mathrm{m}}{ }^{\prime}=200 \mathrm{kPa}, \mathrm{R}^{\prime}=1.5, \mathrm{~b}=0.5$, and $\alpha_{\sigma}=0^{\circ}$, was targeted for specimens I, II and III following the earlier isotropic consolidation tests. Three different stress paths were then followed before finishing at the same stress point of $\sigma_{\mathrm{m}}{ }^{\prime}=200 \mathrm{kPa}, \mathrm{R}^{\prime}=2.5, \mathrm{~b}=$ 0.5 , and $\alpha_{\sigma}=45^{\circ}$, Fig. 8. This involved changing $R^{\prime}$ and $\alpha_{\sigma}$ only, with $b$ and $\sigma_{m}$ ' held 
constant. The actual effective stress components were within $2 \%$ of the targeted values for all the stress paths followed.

The rotation of the major principal stress increment direction, $\alpha_{\Delta \sigma}$, was determined by plotting the test data in terms of shear stress versus normal stress, similar to approach of Roscoe et al. (1967), Fig. 9. Tests II and III appeared as quadrants, centered on the origin and give identical values of $\alpha_{\Delta \sigma}$. Fig. 10 presents the rotation of the major principal strain increment direction, $\alpha_{\Delta \varepsilon}, \square$ which is resolved from the sample strains plotted against $\alpha_{\sigma}$.

The steady increase in $\alpha_{\sigma}$ at constant R' resulted in two distinctly different $\alpha_{\Delta \varepsilon}$ responses. Firstly, when $\alpha_{\sigma}$ rotated for $\mathrm{R}^{\prime}=1.5$ for specimen III, the initially rotation of the major principal strain increment direction was such that $\alpha_{\Delta \varepsilon}=\alpha_{\sigma}+22.5^{\circ}$, which is slightly lower than $\alpha_{\Delta \sigma}$. As $\alpha_{\sigma}$ rotated further, $\alpha_{\Delta \varepsilon}$ approached the vertical direction before moving back towards the $\alpha_{\sigma}$ direction. Secondly, when $\alpha_{\sigma}$ rotated at $\mathrm{R}^{\prime}=2.5$ for specimen II, $\alpha_{\Delta \varepsilon}$ was initially only slightly lower then $\alpha_{\Delta \sigma}$. As $\alpha_{\sigma}$ increased, $\alpha_{\Delta \varepsilon}$ aligned itself closer to $\alpha_{\sigma}$. $\alpha_{\Delta \varepsilon}$ moved towards the $\alpha_{\sigma}$ direction once $\alpha_{\Delta \sigma}$ exceeded $45^{\circ}$ for both specimens. 

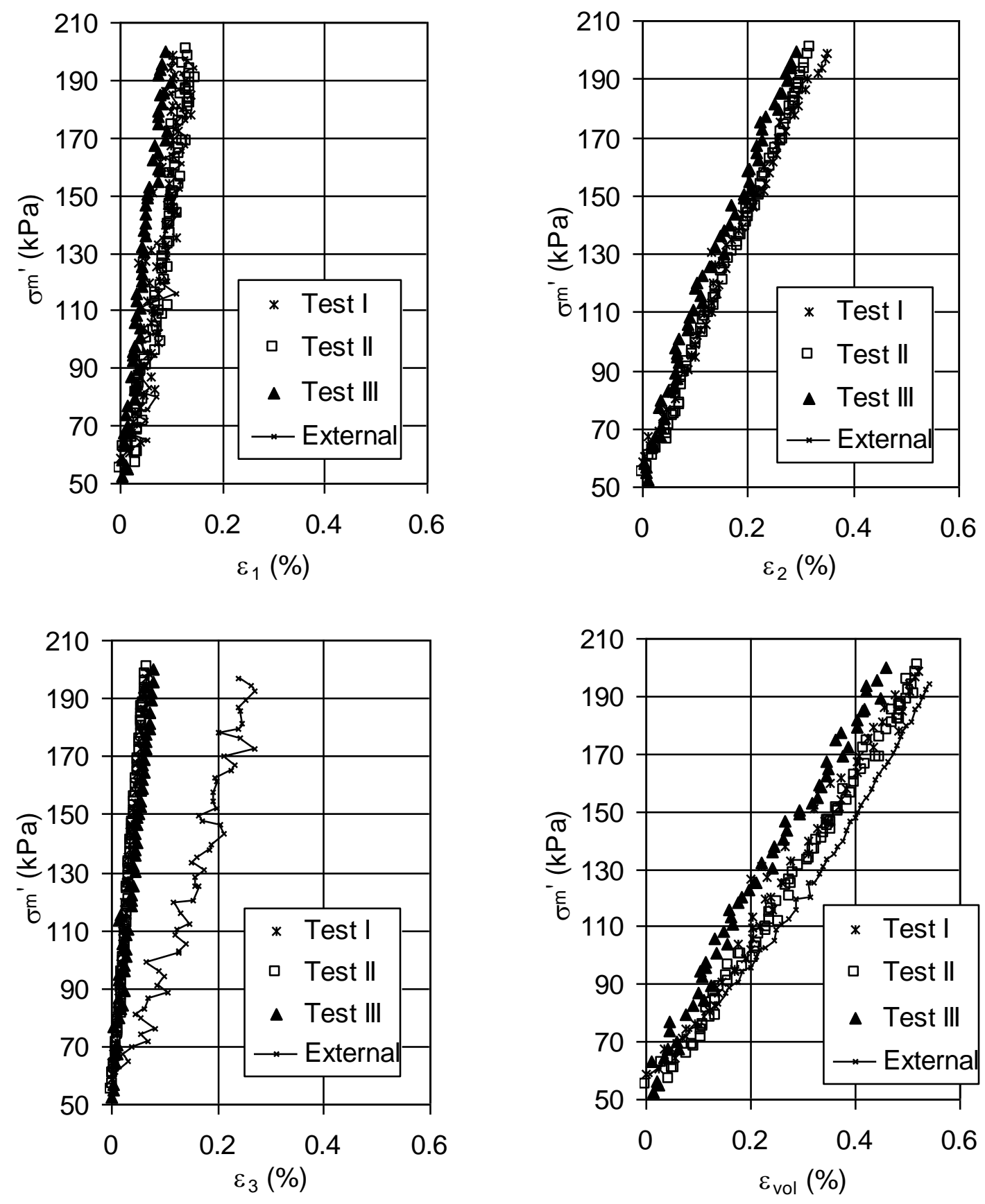

FIG. 7-Principal strain responses of specimens I, II and III for isotropic loading.

The data indicates that for the conditions of R' and $\alpha_{\sigma}$ examined, the rotation of the major principal stress and strain increment directions are initially closely aligned indicating the possibility of an elastic zone for small $\alpha_{\sigma}$ rotations. As $\alpha_{\sigma}$ rotated further, the $\alpha_{\Delta \varepsilon}$ axis realigned itself closer to the $\alpha_{\sigma}$ axis indicating a more isotropic deformational response. This behavior is consistent with observations reported by Roscoe et al. (1967) on the deformational response of Leighton Buzzard sand using the simple shear apparatus. 


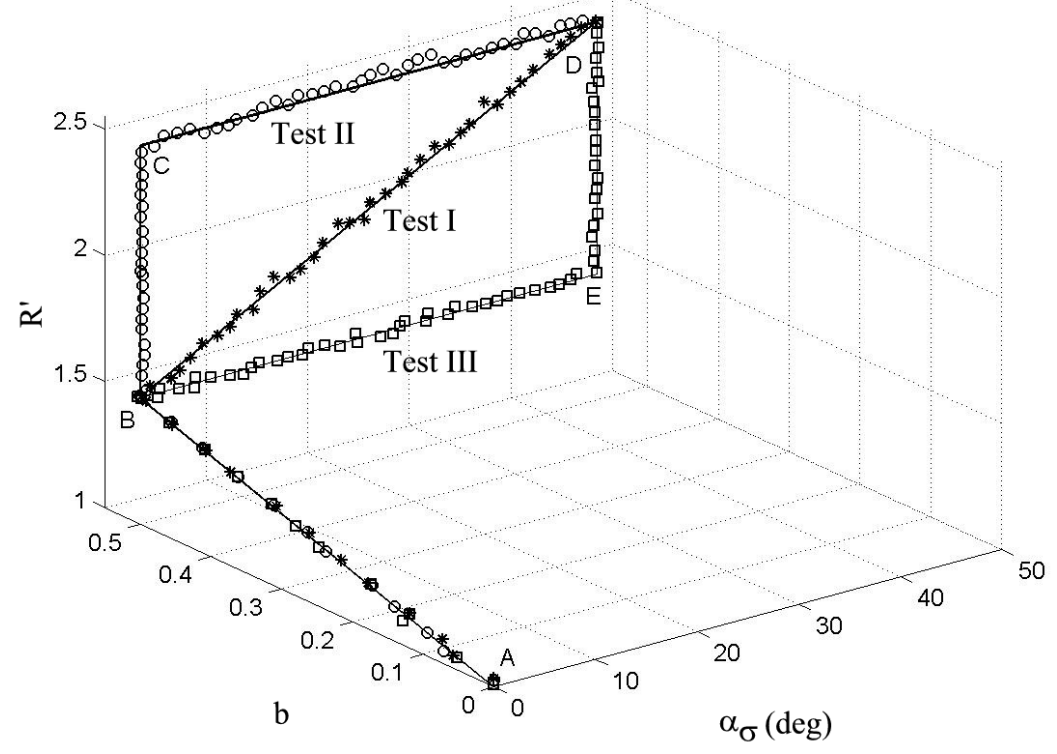

FIG. 8-Target and actual effective stress components for anisotropic loading.

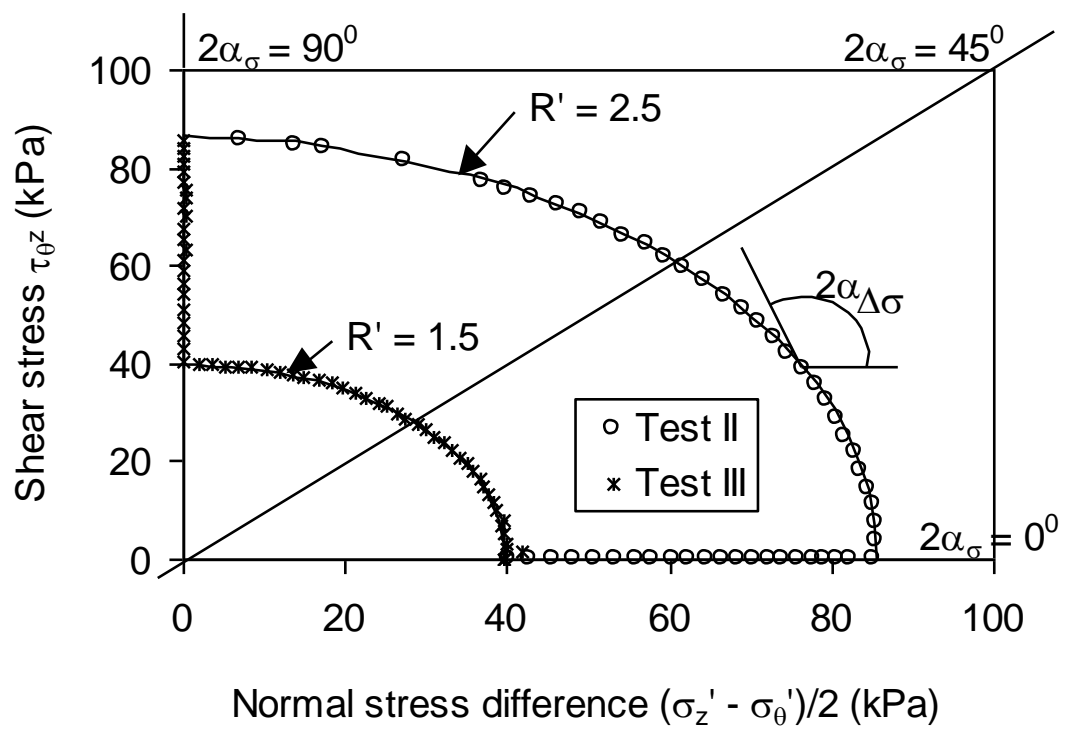

FIG. 9-Anisotropic stress paths in shear stress-normal stress space. 


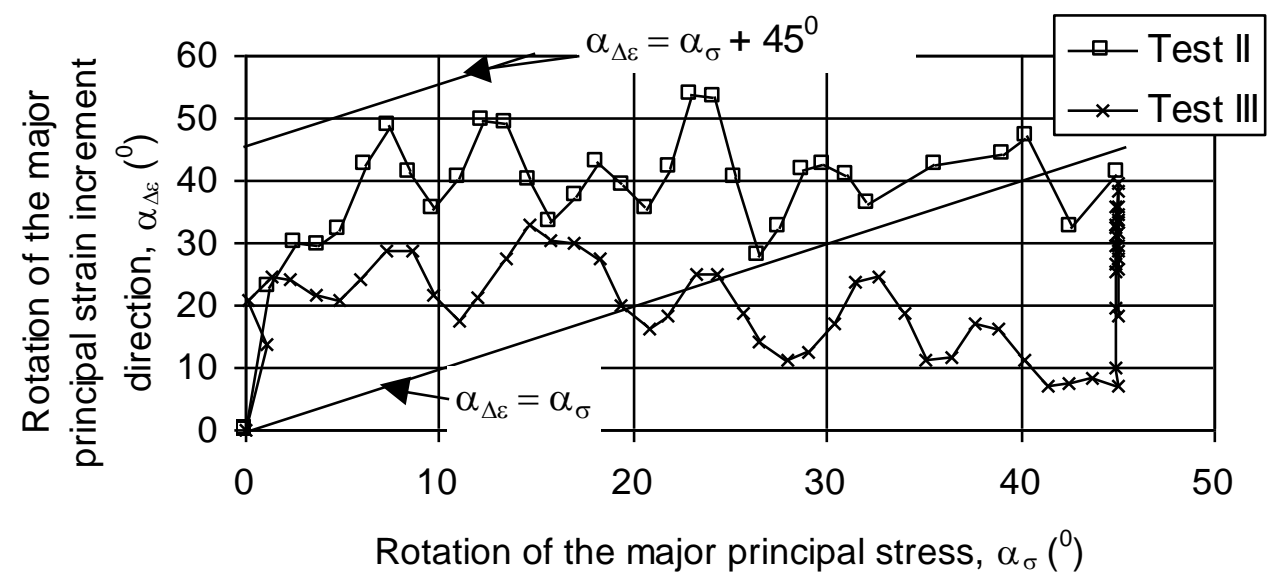

FIG. 10-Rotation of major principal strain increment direction for specimens II and III.

\section{Undrained loading towards failure}

Following the anisotropic stress path tests, specimen III was loading to failure under undrained conditions by increasing the effective major-minor principal stress difference $t$, while maintaining the mean effective confining stress $\sigma_{\mathrm{m}}$, constant, Fig. 11. The mean axial, radial and circumferential total normal stresses remained constant at $350 \mathrm{kPa}$ while the circumferential shear stress was increased from 40 to $250 \mathrm{kPa}$.

The pore water pressure response and the strain components of the specimen increased in magnitude until the phase transformation point $\mathrm{Y}_{4}$, (Zdravkovic and Jardine 2001) was reached before dropping off dramatically. None of the strain components peaked, indicating that the State Bounding Surface had not being reached when the test was ended. The angle of internal friction, determined at the phase transformation point, was calculated as $43^{\circ}$.

Strain response during stress path reversals

The strain response of the specimen during changes in the direction of the stress path was also studied. Fig. 12 presents stress path data in terms of the effective stress components in $\mathrm{R}^{\prime}-\mathrm{b}$ space, for R' initially increasing and then reducing under constant $\sigma_{\mathrm{m}}$, and constant $\alpha_{\sigma}$. The specimen strain responses were initial linear but became increasingly nonlinear as $\mathrm{R}^{\prime}$ increased further. When the direction of the stress path was reversed, causing $\mathrm{R}^{\prime}$ to reduce, the strain responses were generally linear again. Only small changes in the strain components were noticeable when the magnitude of the $b$ parameter was incremented by 0.25 at constant R'. Where R' was increased again, the strain responses were initially linear before becoming slightly nonlinear for higher R' values. These strain responses are similar in form to those reported by Pradel et al. (1990) for similar types of stress path tests on air pluviated Toyoura sand specimens.

\section{Summary and conclusions}

The new hollow cylinder apparatus can capture the stress-strain responses of wet pluviated Leighton Buzzard sand specimens over the intermediate to failure strain levels. The sample dimensions selected limit the development of stress nonuniformity across the sample wall thickness under generalized stress conditions. A screw-spline bearing driven by stepper motors actuates the sample loading piston to 
control the axial and torsional loads applied across the sample length, with negligible backlash evident when the sample loading directions were reversed. A pressure compensation system for the thrust-torque transducer resulted in the axial sample loads being measured independent of the confining pressure changes in the outer cell and inner bore chambers. The mean sample stresses were controlled to within 0.25 $\mathrm{kPa}$ of the target values, with the sample deformations recorded to a resolution of 5.2 x $10^{-3} \%$ strain or better, by a closed-loop control program.

A significant difference was found, in line with other studies, between the sample strains measured using the internal and external instrumentation. The external strain values were significantly larger, with the discrepancy attributed to the difficultly in measuring volume changes of the specimen and its inner bore cavity to the required resolution. Analysis of anisotropic stress path data demonstrated that the new apparatus produced similar rotations of the major principal strain increment direction to those reported by other studies. Furthermore, analysis of stress path data which involved stress path reversals showed similar strain characteristics to other studies.

\section{Reference:}

Ampadu, S. K. and Tatsuoka, F., 1993, "A hollow cylinder torsional simple shear apparatus capable of a wide range of shear strain measurement", Geotechnical Testing Journal, Vol. 16, No. 1, pp. 3-17.

Brown, S. F., Austin, G. and Overy, R. F., 1980, “An instrumented triaxial cell for cyclic loading of clays", Geotechnical Testing Journal, Vol. 3, No. 4, pp. 145-152.

Burland, J. B. and Symes, M.,1982, "A simple axial displacement gauge for use in the triaxial apparatus", Geotechnique, Vol. 32, No. 1, pp. 62-65.

GDS Instruments Ltd., 1998, “GDS 2MPa/200cc advanced pressure/volume controller”, Technical literature.

Hight, D. W., Gens, A. and Symes, M. J., 1983, “The development of a new hollow cylinder apparatus for investigating the effects of principal stress rotation in soils", Geotechnique, Vol. 33, No. 4, pp. 355-383.

Lo Presti, D. C. F., Pallara, O., Lancellotta, R., Armandi, M. and Maniscalco, R., 1993, "Monotonic and cyclic loading behaviour of two sand at small strains". Geotechnical Testing Journal, Vol. 16, No. 4, pp. 409-424.

Miura, K., Miura, S. and Toki, S., 1986, "Deformation behaviour of anistropic dense sand under principal axes rotation”, Soils and Foundations, Vol. 26, No. 1, pp 36-52.

Menkiti, O.C., 1995, "Behaviour of clay and clayey-sand, with particular reference to principal stress rotation", $\mathrm{PhD}$ Thesis, University of London, UK.

O'Kelly, B.C. and Naughton, P.J., 2004, "The Properties of Wet Pluviated Hollow Cylindrical Specimens" Paper under review for Geotechnical Testing Journal, ASTM.

Pradel, D., Ishihara, K. and Gutierrez, M., 1990, "Yielding and flow of sand under principal stress axes rotation", Soils and Foundations, Vol. 30, No. 1, pp 87-99.

Porovic, E., 1995, "Investigations of soil behaviour using a resonant column torsional shear hollow cylinder apparatus", $\mathrm{PhD}$ thesis, University of London, UK.

Saada, A. S. and Puccini, P. M., 1986, Discussion on "Deformation behaviour of anisotropic dense sand under principal stress rotation”. Soils and Foundations, Vol. 26, No. 4, pp. 159160 .

Roscoe, K.H., Bassett, R.H. and Cole, E.R.L., 1967, "Principal axes observed during simple shear of a sand". 4th European Conf. on Soil Mech. and Foundation Engineering, Oslo, pp 231-237.

Sivathayalan, S. and Vaid, Y. P., 1998, "Truly undrained response of granular soils with no membrane penetration effects", Canadian Geotechnical Journal, Vol. 35, pp. 730-739. 
Symes, M. J. and Burland, J. B., 1984, "Determination of local displacements on soil samples", Geotechnical Testing Journal, Vol. 7, No. 2, pp. 49-59. 

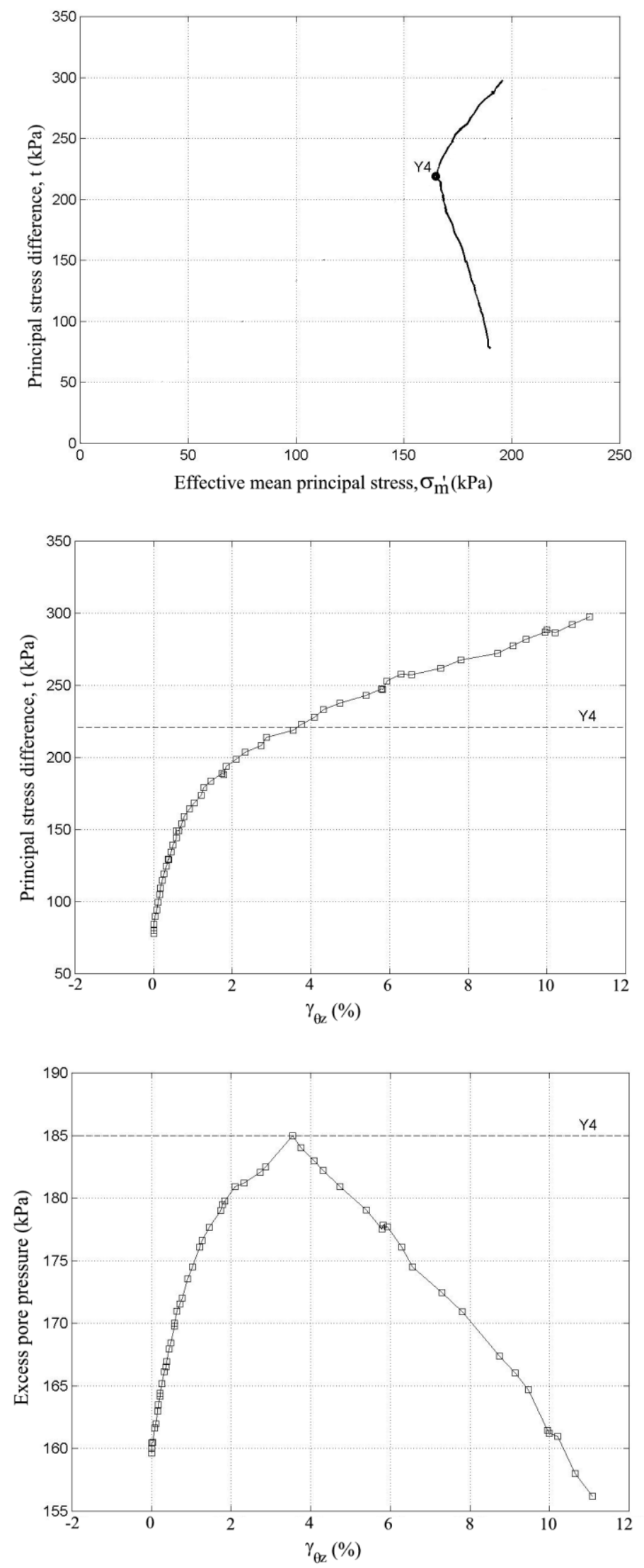

FIG. 11-Constitutive response of specimen III under undrained loading. 

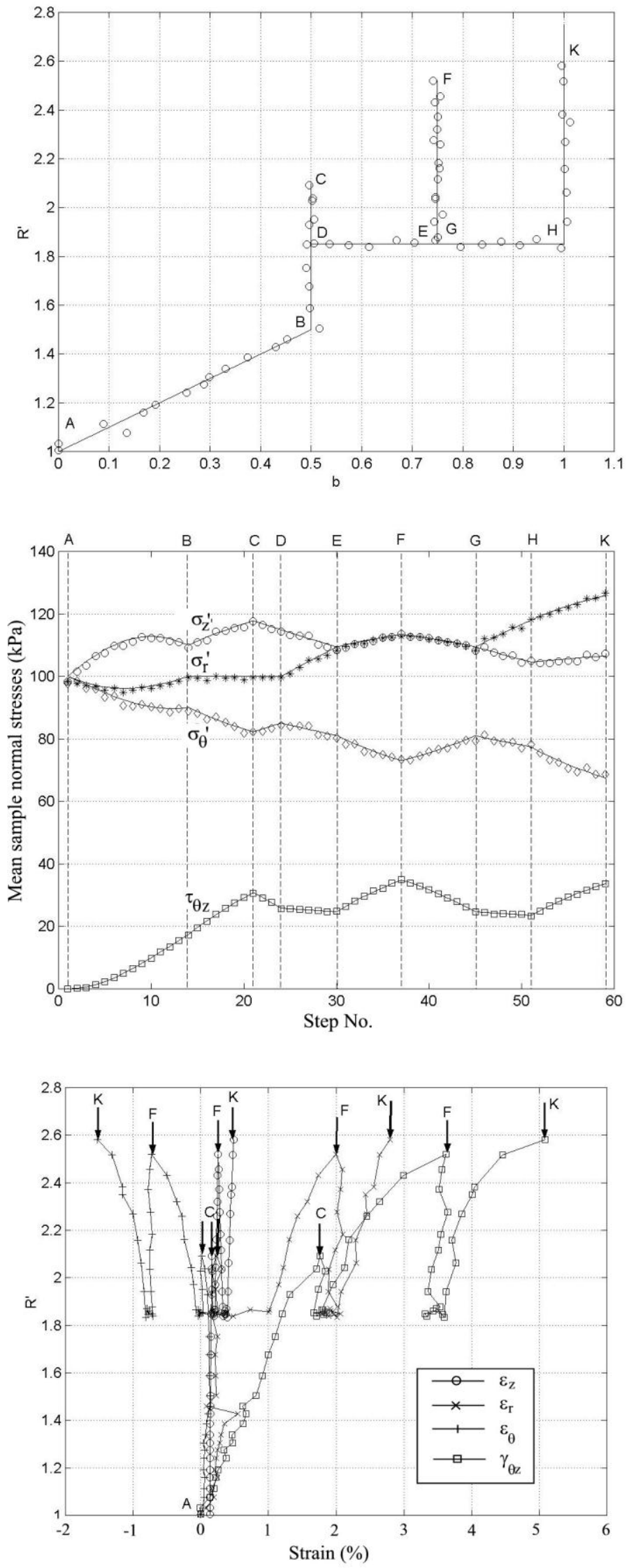

FIG. 12-Constitutive response for load-unload stress path. 
Tatsuoka, F., Sonoda, M., Hara, K., Fukushima, S. and Pradhan, T. B. S., 1986, "Failure are strength deformation of sand in torsional shear", Soils and Foundations, Vol. 26, No. 4, pp. 79-97.

Tatsuoka, F., Muramatsu, M. and Saski, T. 1983. Closure, Cyclic undrained stress-strain behaviour of dense sands by torsional simple shear tests. Soils and Foundations, Vol. 23, No. 3, pp. 142-145.

Vaid, Y. P., Sayao, A., Hou, E. and Negussey, D., 1990, “Generalized stress path dependent behaviour with a new hallow cylinder torsional apparatus", Canadian Geotechnical Journal, Vol. 27, pp. 601-616.

Wijewickreme, D. \& Vaid, Y.P., 1991, "Stress nonuniformities in hollow cylinder torsional specimens”. Geotechnical Testing Journal, Vol. 14, No. 4, pp. 349-362.

Zdravkovic, L. and Jardine, R.J., 2001, "The effect on anisotropy of rotating the principal stress axis during consolidation”, Geotechnique, Vol. 51, No. 1, pp 69-83. 